\title{
A STUDY OF THEORETICAL AND EXPERIMENTAL OF COOLING PROCESS IN A GEOTHERMAL ENERGY SYSTEM BY USING A PROTOTYPE
}

\author{
ODAY A. ABBo \\ Dept. of Mechanical Engineering, College of Engineering, University of Duhok, \\ Kurdistan Region, Iraq
}

(Received: February 21, 2021; Accepted for Publication: June 6, 2021)

\begin{abstract}
An Experimental and Theoretical of horizontal geothermal heat Exchanger which is investigated by using a prototype, Experimental setup depend on Thermoelectric Peltier kits to give required cooling or heating for grout. A closed loop system pump and borehole heat exchanger tested in by using Horizontal helical polyethylene pipes with a diameter inside that equal $4 \mathrm{~mm}$ which immersed in a grout. Our Goal is to improve the rig design by using analytical solution.

A theoretical analysis was improved for horizontal ground heat exchangers (HGHEs) which integrate with water pump by using the basic equation of two-dimensional conduction convection heat transfer for laminar flow $500<\operatorname{Re}<2300$, Basic analysis is made for Trench method with doubles pipes as whole resistance borehole. Compression between Theoretical and experimental is made with different temperature and the water mass flow rate is between 0.0014 to $0.0063 \mathrm{~kg} / \mathrm{s}$. the result of Nusselt Reynolds Numbers gave a good indication of the efficiency for the device which is between 20 to $80 \%$ depend on Reynolds Number, Heat exchanger effectiveness also prepares the low Reynolds Number gave high effectiveness as compared with higher Reynolds Number dependence on water residence time inside HGHE. A comparison between Experimental and theoretical gave an error less than $5 \%$ difference.

Result show that device can use to improve the researches in use of geothermal resource and heat pump analysis by choosing the best parameter which found by prototype in actual case.
\end{abstract}

Keywords: Horizontal heat exchanger; Heat transfer; Geothermal; Energy efficiency.

Symbols and abbreviations

Symbols

Latin letters

b Eccentricity parameter

$\mathrm{Cw} \quad$ Specific heat of water

Dring Ring Diameter

$D_{h} \quad$ Horizontal Ring Diameter

D $\quad$ Vertical Ring Diameter

dout Tube outer diameter

din |Tube inside diameter

$h_{\text {exp }} \quad$ Experimental convective heat

transfer coefficient

Theoretical convective heat transfer coefficient

Thermal conductivity pf grout

Thermal conductivity of pipe

Pipe Length

Trench Length

Mass flow rate

Nusslet Number

Number of Transfer Units Method

Pitch of ring trench

PolyEthlyne

Heat Flow

Heat Flow

Heat flow per length

Effective steady-flux thermal

resistance

Internal resistance between pipes

Thermal resistance of the grouting

material

Thermal resistance of the tube

Reynolds Number

\begin{tabular}{|c|c|c|c|}
\hline & $\mathrm{T}_{\text {in }}$ & Water inlet temperature & C \\
\hline & $T_{\text {out }}$ & Water Outlet Temperature & C \\
\hline $\begin{aligned} \mathrm{J} / \mathrm{kg} \cdot \mathrm{K} \\
\mathrm{m}\end{aligned}$ & $\overline{T_{s-p}}$ & $\begin{array}{l}\text { Average temperature at the surface } \\
\text { Grout -pipe interface }\end{array}$ & C \\
\hline $\mathrm{m}$ & $\overline{T_{f}}$ & Mean fluid temperature & C \\
\hline & UA & heat transfer capacity & $\mathrm{W} / \mathrm{K}$ \\
\hline & v & velocity & $\mathrm{m} / \mathrm{s}$ \\
\hline$w /\left(m^{2} \cdot k\right)$ & \multicolumn{3}{|c|}{ Greek letters } \\
\hline & $\mu$ & Viscosity & $\mathrm{Kg} / \mathrm{m} . \mathrm{s}$ \\
\hline$W /\left(m^{2} \cdot k\right)$ & $\rho$ & Density & $\mathrm{Kg} / \mathrm{m} 3$ \\
\hline $\begin{array}{l}W /(m \cdot k) \\
W /(m \cdot k)\end{array}$ & $\varepsilon_{\text {ghe }}$ & $\begin{array}{l}\text { Effectiveness of geothermal heat } \\
\text { exchanger }\end{array}$ & \\
\hline $\mathrm{m}$ & subscript & & \\
\hline $\mathrm{m}$ & $\mathrm{h}$ & Horizontal & \\
\hline \multirow[t]{2}{*}{$\mathrm{Kg} / \mathrm{s}$} & v & Vertical & \\
\hline & $\mathrm{p}$ & pipe & \\
\hline \multirow[t]{2}{*}{$\mathrm{m}$} & $\mathrm{t}$ & Trench & \\
\hline & \multicolumn{2}{|c|}{ Abbreviations } & \\
\hline W & GHE & Geothermal Heat Exchanger & \\
\hline $\begin{array}{r}W \\
W / m\end{array}$ & HGHE & Horizontal Grout heat Exchanger & \\
\hline$(m \mathrm{k}) / \mathrm{W}$ & HGCHP & Hybrid ground coupled heat pump & \\
\hline & $\mathrm{PE}$ & Polyethylene & \\
\hline $\begin{array}{l}(\mathrm{m} . \mathrm{k}) / \mathrm{W} \\
(\mathrm{m} \cdot \mathrm{k}) / \mathrm{W}\end{array}$ & TEC & Thermoelectric cooler & \\
\hline $\mathrm{k}) / \mathrm{W}$ & & & \\
\hline
\end{tabular}

oday.adnan@uod.ac 


\section{1-INTRODUCTION}

$\mathbf{T}$ The major advantage of geothermal systems is their economical operation cost compared to all the other systems. Because of high temperature of summer in the Middle Eastern countries which makes the direct used of geothermal cooling systems which is no effective that is why it is not dependable but during last year's geothermal heat exchanger system combined with heat pump or airconditioning device can increase the coefficient of performance rapidly and reduce the power consumption [1].

. The first prototype was installed in USA 1945, latter many prototypes installed to invisgate the thermal performance, while previous research studies previous full meaning of understanding the system performance, these tests are sitespecific and there are complex to analyze comprehensively due to given uncertainties inside site conditions. In the other hand, A design of the laboratory tests can be giving more clarity over full-scale tests because the change of soil properties can be controlled and measured more easily in laboratory than in the field [1].

The effect of soil temperature change during year for Geothermal Heat Exchanger GHE is studying by [3] using mathematical model by applying an energy balance on the ground surface for $U$ tube heat exchange from the analysis model we can find the effects of the pipe length, mass flow rate of fluid, fluid inlet temperature, and the depth of burial on the fluid and heat transfer performance of the horizontal geo heat exchanger.

[4] show that heat flow occurs at the outer wall of HGHE and in the direction of inclines, also it will be more stable at far-field, they founded that the fluid inlet temperature and the starting temperature of grout with the flow rate are basic parameters affecting on thermal characteristic. The advantages of the HGCHP System less expensive to install than vertical closed loop because trenching is generally less expensive than drilling also its requires less specialized skill and equipment to install, so contractors are more widely available [1] . but there is some disadvantages like Requires more space, more piping, Ground temperature and thermal properties fluctuate with season, rainfall, and burial depth.
The aim of building laboratory prototype is to controlled to be able to isolate and to achieve more a knowledge about the main function variables while minimizing error analysis. Another main advantages of prototype tests, those described in this paper, is that multiple tests can easily done by achieved under all controlled testing conditions. Controlled in many parameters of the laboratory experiment can be support in providing full meaning for the Thermal and fluid of a complex process. Moreover, the results which got it from the parameters change inside laboratory experiments, which presented in this paper, can be used to as indicated to verify the predictions which took from mathematical and numerical models of heat transfer for HGHE.[4]

Previous laboratory-prototype which a achieved on model of geothermal piles include a series of centrifuge tests at more than one like in the University of Colorado at Boulder, [5] These study either were limited to use for vertical geothermal heat exchanger for transient heat transfer. The laboratory experiments for horizontal is presented in this research studies the thermal behavior of a model HGHE with poly ethylene tube PE while varying of parameters such as fluid mass flow rate and fluid inlet temperature (and thus, the initial temperature gradient) can controlled. Such parameters help to understand the effects of different operational parameters on thermal behavior of HGHE which help in the development of economically and highperformance efficient system of horizontal heat exchanger systems. Data presented in this research provided full meaning insight the complex thermal fluid process through heat exchanger tubes and can also be used for verifying results from numerical model.

Our goal is to improve geothermal systems and solve this problem by using prototype to open a wide range of research gate in this field by invited special device can serve this job, so that it would be dependable throughout the seasons. four basic types are mentioned for ground loop heat exchanger systems [2], its horizontal, vertical, with closed-loop systems, Third one is the open-loop system. Which one of these are best depends on the season condition, soil specification, available land, and the installation costs at the field. All of these approaches can be used for residential and building applications. 


\section{2- EXPERIMENTAL RIGS \& SYSTEM} COMPONENTS

\section{2-1 Heat Exchanger (Grout Box)}

The schematic diagram for the laboratory device is given in Figure (1). The prototype is consisting of two main units: soil box which represent HGHE it represented by glass walls with a thin aluminum base to reject heat from the soil tube, which is immersed between $5 \mathrm{~cm}$ of soil upper and $5 \mathrm{~cm}$ lower, which its photograph is show in Figure 2 .

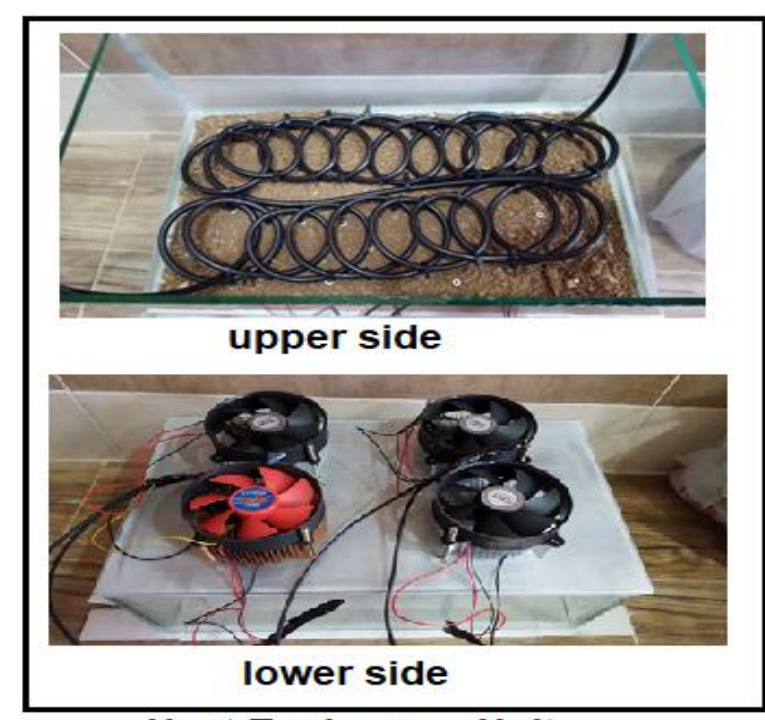

Heat Exchanger Unit

Fig. ( 1): Layout of Experiment assembled rig

Fig. (2): Photograph of a complet

The HGHE consists of a polyethylene tube arranged as sketch in Figure 3, specification see in table 1.

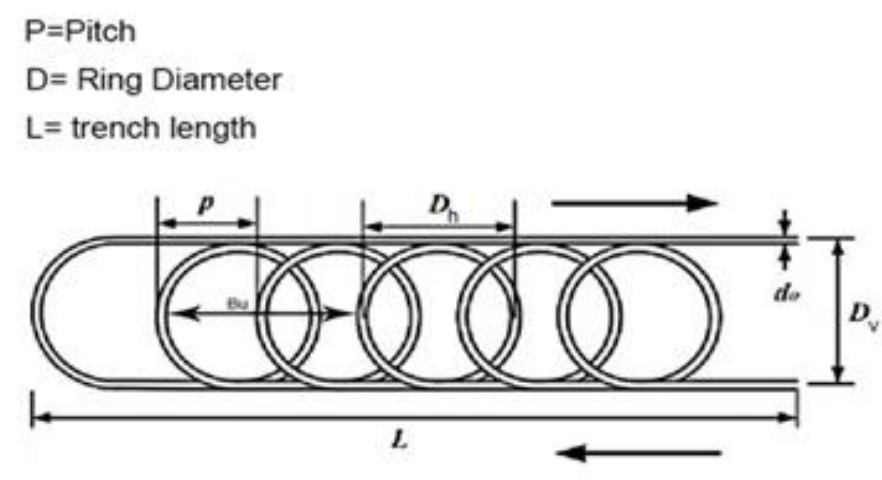

Fig. (3): Pipe Diagram

A typical Grout used which is formulated from $80 \%$ soil\&20\% grain steel [7]. Water supplied to heat exchanger by using high pressure water pump, control of flow is satisfied by bypass valve different tests with different inlet hot water temperature are used. The specifications and the components detail of the system are given in Table 1 . 
Table (1): Heat Exchanger specification

\begin{tabular}{ll}
\hline Pipe inside diameter $\mathbf{d}_{\text {pin }}(\mathbf{m m})$ & $\mathbf{4}$ \\
\hline Pipe out side diameter $\mathrm{d}_{\text {pout }}(\mathrm{mm})$ & 6 \\
\hline $\mathrm{D}_{\text {ring }}(\mathrm{mm})$ & 8 \\
\hline Eccentricity Parameter $\mathrm{b}$ & 0.9 \\
\hline Pipe thermal conductivity $(\mathrm{W} / \mathrm{m} . \mathrm{K})$ & 0.4 \\
\hline Grout Thermal conductivity $(\mathrm{W} / \mathrm{m} . \mathrm{K})$ & 2.25 \\
\hline Length of pipe $(\mathrm{m})$ & 6 \\
\hline Trench Length $\mathrm{m}$ & 0.4 \\
\hline Number of Trench & 2 \\
\hline Box Size $(\mathrm{cm})$ & $50^{*} 35$ \\
\hline
\end{tabular}

\section{2-2 Heating \& Cooling (Thermoelectric cooler (Peltier)) system}

Four thermoelectric pieces installed in the bottom of device to provide an efficient cooling which depend on the Peltier effect technology which supply a constant heat flux between the metal junctions are made from two different types of materials. The type we use is TEC112706 [8] as show in figure 4. Inside every kit there is a 127 couples, $40 \mathrm{~mm} \times 40 \mathrm{~mm}$ size from one stage module is made of selected high performance to achieve high efficient cooling performance and the greater different temperature between hot and cold side can reach up to $70{ }^{\circ} \mathrm{C}$, designed for the maximum cooling and heating up to $100{ }^{\circ} \mathrm{C}$ requirement. 12 volt Dc supplier with $30 \mathrm{Amp}$. Capacity used to supply the required power to kits.

The purpose of using this device is to absorb heat from the soil (Grout) and reject it to the outside environment until the desired temperature is reached. Kept the soil Temperature as underground temperature between 15 to $20 \mathrm{C}$ according to test require. Fan and Heat sink component are used to reject heat to ambient out of thermoelectric device, An digital temperature controller are used to controlled the value of temperature desired temperature by used Thermocouples which is touched the lower surface of the device.
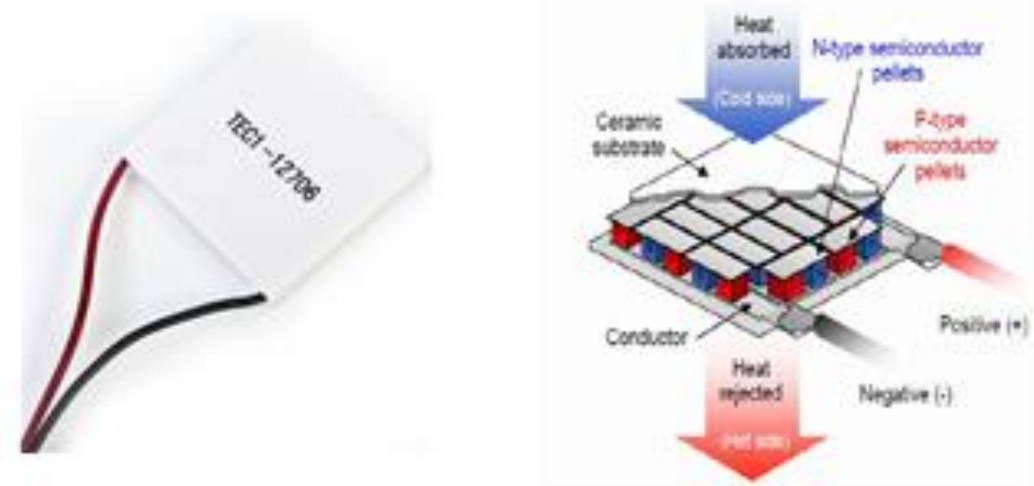

Fig. (4): Thermoelectric kit

\section{2-3 Measuring data}

The aim of device is measuring outlet temperature and inlet temperature of water by using thermometer which put in the water flow pipe from hot tank (inlet temperature) and another one in the flow to the cooling tank which represent the outlet temperature, mass flow is predicted by using laboratory flask for water out let towards cold tank, flow controlled by the by pass valve see figure $1 \& 2$ for more detail.
Cooling system kept constant cooling flux to the grout by the thermal control system.

\section{2-4 Experimental analysis}

Experimental analysis is made under the relation [9]n:

$$
\begin{aligned}
Q_{\text {exp }}^{\prime}=q_{i} L & =m \cdot C_{w}\left(T_{\text {in }}-T_{\text {out }}\right) \\
N u_{\text {exp }} & =\frac{h_{\text {exp }} d_{p i}}{K_{f}}
\end{aligned}
$$


Where Q Heat flow rate in Watt, qi heat flow per unit length $\mathrm{W} / \mathrm{m}, \mathrm{m}$ mass flow rate in $\mathrm{kg} / \mathrm{s}$, $\mathrm{C}_{\mathrm{w}}$ is specific heat of water, $\mathrm{Nu}$ Nuslet Number and $h_{\text {exp }}$. Experimental heat transfer coefficient. $\mathrm{d}_{\mathrm{p}}$, inside diameter of tube. Heat transfer Coefficient is founded by [9] Jack P. Holman.

$$
\begin{aligned}
h_{\text {exp }} & =\frac{Q_{\text {exp }}^{\prime}}{\pi d_{p i} L\left(T_{\text {in }}-T_{\text {out }}\right)} \\
R e & =\frac{v d_{\text {pi }} \rho}{\mu}
\end{aligned}
$$

Where Re. is Reynolds Number. V is velocity, $\rho$ is density, $\mu$ viscosity.

\section{3-MATHEMATICAL MODEL}

Analysis of thermal hydrodynamic behavior of HGHE must be able to predict by the heat transfer rate $\mathrm{Q}$ by founding the total heating resistance of device and then we can predict water out let water temperature $\mathrm{T}_{\text {out }}$, for the pump dimensioning and operation consideration.
The evaluation of efficiency basically by water inlet temperature $T_{\text {in }}$ and mass flow rate $\mathrm{m}$.

The Enthalpy drop of the fluid basically depends on geostructure energy with pipe type and thickness [10] under this condition the heating value effects are nonessential and geostructure will be more confided to behave as a typical. It will be deal as a model heat exchanger characterized by an equivalent thermal resistance between the PE tube and the ground. The classical effectiveness number of heat transfer units (Eghe -NTU) method for heat exchanger [11]. Which be used for the rig which designed and deal with it as stable condition the effect of grout will be steady by time due to working of Thermoelectric kits to estimate the heat flow occurring in energy inside the geothermal and to show the thermal behavior of these heat exchangers for different tube size and shape installed. When considering the Eghe NTU model for energy piles, for example, as in the following equations apply [12] :

$$
\begin{aligned}
& Q \cdot=q_{i} L=m \cdot C p_{f}\left(\overline{T_{\text {in }}-T_{\text {out }}}\right)=U A\left(\overline{T_{f}-T_{s-p}}\right)=U A\left(\overline{T_{f}}-\overline{T_{s-p}}\right) \\
& q_{i}=\frac{\left(\overline{T_{f}}-\overline{T_{s-p}}\right)}{L}- \\
& U A=\frac{L}{R_{\text {ghe }}^{\prime}}
\end{aligned}
$$

According to our design $R_{\text {ghe }}^{\prime}$ Represent the total resistance of the system, UA is heat transfer capacity, $\overline{T_{s-p}}$ in equation 1 represent the average temperature at the surface Grout -pipe interface. The basic formula can applied to the mean fluid temperature $\bar{T}_{f}$ can be used in the analysis through Eq. (5), this for a little defiance among $\mathrm{T}_{\text {in }}$ and $\mathrm{T}_{\text {out }}$.

Figure (5) shows the thermal resistance of HGHE by [1] mainly there is two thermal resistances, one is a thermal resistance for convection, R'conv, and other is for conduction, R'cond, can be specified and its suppose to be connected in series to describe the three for mentioned above processes. The summation of this thermal resistances to the time-independent for the effective thermal resistance of the geothermal heat exchanger as:

$$
R_{\text {ghe }}^{\prime}=R_{\text {conv }, p}{ }^{\prime}+R_{\text {cond }, p}^{\prime}+R_{\text {cond,c }}{ }^{\prime}
$$




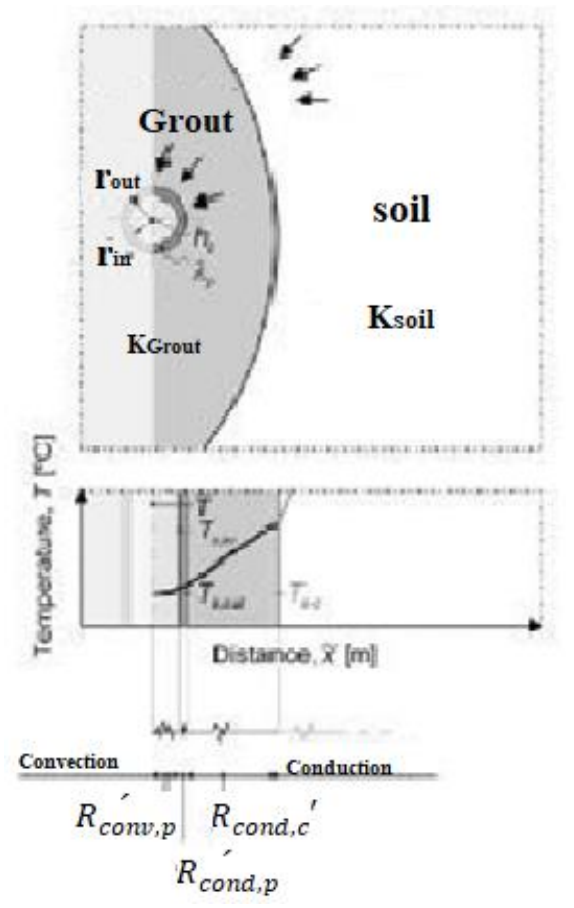

Fig. (5): The thermal resistance sketch applied to energy piles

Where $R_{\text {conv,p, }}{ }^{\prime} R_{\text {cond,p } p}$ and $R_{\text {cond,c }}$ are the effective thermal resistances that its grouped for the mentioned above phenomena (1), (2) and (3), respectively, with $\mathrm{R}_{\text {conv }}^{\prime}+R_{\text {cond,p }}^{\prime}=R_{, p}^{\prime}$ the thermal resistance of the tube and $R_{\text {cond,c }}$ the thermal resistance of the grouting material. To find Total resistance Two dimensional steady flow heat flux is introducing with thermal $\Delta$ circuit is analysis for Two pipe put in Horizontal duct

Figure
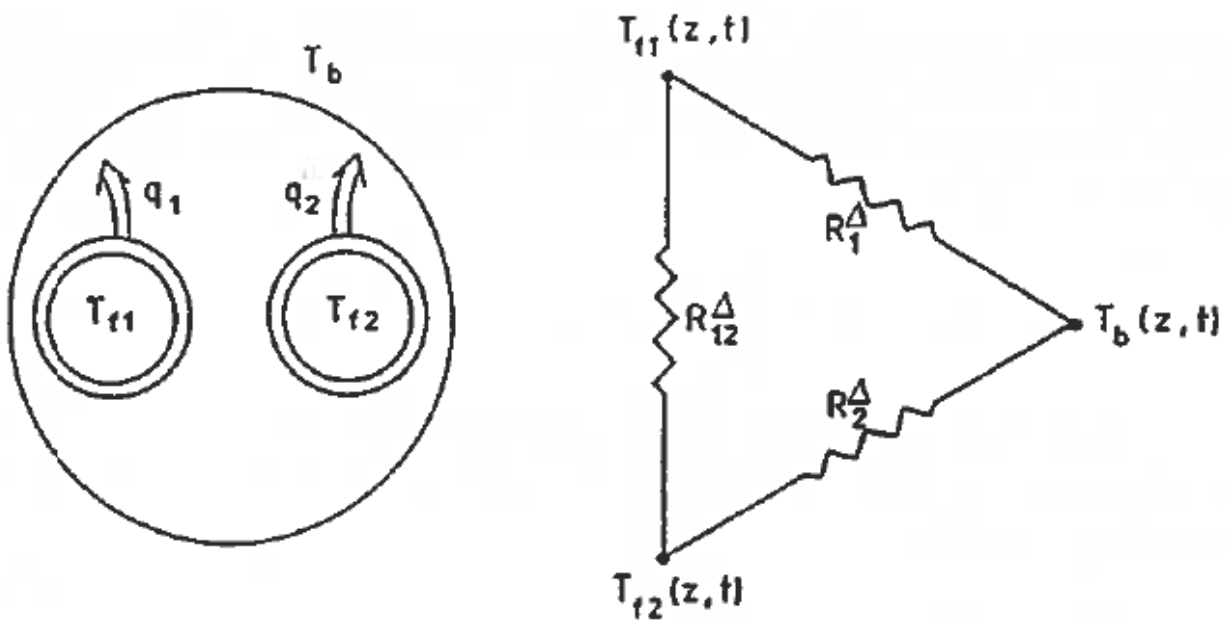

Fig. (6): Cross section of the bore hole and corresponding thermal $\Delta$ circuit is introduce [13]

For two pipe in HGHX is given By [13]:

$R_{\text {ghe }}=R_{\text {ghe }}+\frac{1}{3} \frac{1}{R_{a}^{\prime}}\left(\frac{H}{C}\right)^{2}$
Where the PE tube (pipe) inside trench are approximated as a line source in circular region.. $R_{\text {ghe }} \quad$ is an effective steady-flux thermal resistance, $R_{a}$ is an internal resistance between pipes, $H$ is the trench length, and $C$ is the heat capacity rate of the heat transfer fluid. The 
intermediate resistances are given for a two-pipe, The Thermal resistance between two pipes is

given

also

by

[13]:

$$
\begin{aligned}
& R_{\text {ghe,two,pipe }}=\frac{1}{2 \pi k_{\text {grout }}}\left[\ln \left(\frac{r_{\text {trench }}}{r_{p, \text { out }}}\right)-\frac{3}{4}+b^{2}-\frac{1}{2} \ln \left(1-b^{4}\right)-\frac{1}{2} \ln \left(\frac{B_{u}}{r_{p, \text { out }}}\right)\right]+\frac{R_{, p}^{\prime}}{2} \\
& R_{\text {a,two pipe }}^{\prime}=\frac{1}{\pi k_{\text {grout }}}\left[\ln \left(\frac{2 \text { br trench }}{r_{p, \text { out }}}\right)-\ln \left(\frac{1-b^{2}}{1+b^{2}}\right)\right]+2 R_{p}^{\prime} \\
& R_{p}^{\prime}=\frac{1}{\pi * D_{p, \text { in }} * h_{\text {in }}}+\frac{\ln \left(\frac{D_{p, \text { out }}}{D_{p, \text { in }}}\right)}{2 * \pi * k_{p}}
\end{aligned}
$$

Where $\quad b=\frac{D_{h}}{D_{v}}=0.9$ eccentric value, $D_{\text {trench }} 0.01 \mathrm{~m}, H=0.8 \mathrm{~m}$ ( for two trench) each $40 \mathrm{~cm}\left(\mathrm{~L}_{\text {trench }}\right)$.

Under a uniform surface heat flow of PE pipe with soil interface, $\overline{T_{s-p}}=\mathrm{T}_{\mathrm{sp}}$, the HGHE effectiveness, $\varepsilon_{g h e}$, is represents the ratio of the real heat transfer rate and the optimum possible heat transfer rate of the heat exchanger, which is the difference between max and min temperature inside prototype system [11]:

$\varepsilon_{\text {ghe }}=\frac{\overline{T_{\text {out }}}-\overline{T_{l n}}}{T_{s-p}-\overline{T_{l n}}}$

We choose this method because our design consideration is built with Constant Grout heat flux use of the effectiveness _NTU ( $\varepsilon_{g h e}$-NTU) method for the analysis of this geothermal model, the thermal energy at the surface of the grout to pipe surely can assumed dependably on the temperature variation of the fluid, $T_{\text {in }}-T_{\text {out }}$. The main reason for this assumption is that the exit fluid temperature is imposed to be always more or lower (according cooling or heating) than the temperature at the soil-pile interface depending on the heat flux flow of the thermal energy, consequently. This fact prevents of inconsistent analysis results that may arise as a consequence of the use of the mean temperature in terms of the local direction of heat transfer because of the little temperature drop between the fluid and the ground [12].

The $\varepsilon_{g h e}$-NTU method is a good tool to improve high precession analyses on the impact of different design solutions on the geothermal heat exchange.
Another factor which can compare with $\varepsilon_{g h e^{-}}$ NTU is the NTU Theoretical which is depended on over all heat transfer coefficient [14]:

$N T U_{t h}=\frac{U A}{m \cdot c p}$

Efficiency of HGHE is calculated by evaluate maximum heat transfer along it from the following formula:

$$
Q_{\max }^{\prime}=m \cdot C w \quad\left(T_{o u t}-T_{s-p}\right)
$$

Grout are typically it's a mixed from a finegrain clays and coarse-grain sands. A separation analysis can be approved to determine the percentage of the components that are coarse grain and fine grain. A weighted average was calculated $\mathrm{k}_{\text {grout }}=2.25$ [7]. Thermal conductivity of poly ethylene pipe is found from [1]:

$N u_{t h}=\frac{h_{t h} d_{p i}}{K_{f}}$

Where $h_{t h}$ is founded from

$$
h_{t h}=\frac{Q_{t h}^{\prime}}{\pi d_{p i} L\left(T_{\text {in }}-T_{\text {out }}\right)}
$$

\section{4-RESULTS AND DISCUSSION}

Table 2 show measuring and analyzing data for the inlet and outlet temperature, Heat exchange rate theoretical, experimental and Reynolds No.. The data gave an indication that outlet temperature reduce with less value of mass flow rate until reach to constant temperature at $\operatorname{Re}<500$ but the heat exchange rate for both experimental and theoretical increase in opposite side, To reach the maximum Heat rate at $\operatorname{Re}<2267$ which is near the maximum. Reynolds No. for laminar flow. 
Table (2): Measuring and heat flow estimate data

\begin{tabular}{cccccc}
\hline $\mathrm{m}$ & $\mathrm{T}_{\text {out }} \mathrm{C}$ & $\mathrm{T}_{\text {in }} \mathrm{C}$ & $\mathrm{Q}_{\exp }$ Watt & $\mathrm{Q}_{\text {th }}$ Watt & $\mathrm{Re}$ \\
\hline 0.00633 & 37.5 & 40 & 66.14 & 71.72 & 2267.458 \\
\hline 0.0032 & 32.5 & 36 & 46.81 & 52.27 & 1146.266 \\
\hline 0.00231 & 31.5 & 36 & 43.45 & 49.92 & 827.461 \\
\hline 0.001525 & 30 & 36 & 38.24 & 46.21 & 546.2676 \\
\hline 0.00142 & 30 & 36 & 35.61 & 46.06 & 508.6557 \\
\hline
\end{tabular}

Difference between Heat rate theoretical and Experimental around $10 \%$ and increase to $12 \%$ at low Re, its appear due to affected of air between the grout grain which increase the thermal resistance in actual case.

Figure 8 shows Reynolds \& Nusselt numbers relation which indicated behavior of flow with heat transfer from grout to water that $\mathrm{Nu}$. No increase linearly with the Reynolds number. Difference between Theoretical and Experimental at Reynolds No. less than 1000 is less $20 \%$ because the time independency is less, water need more time inside pipes and the function of time will be dependab ly increasin $\mathrm{g}$ the

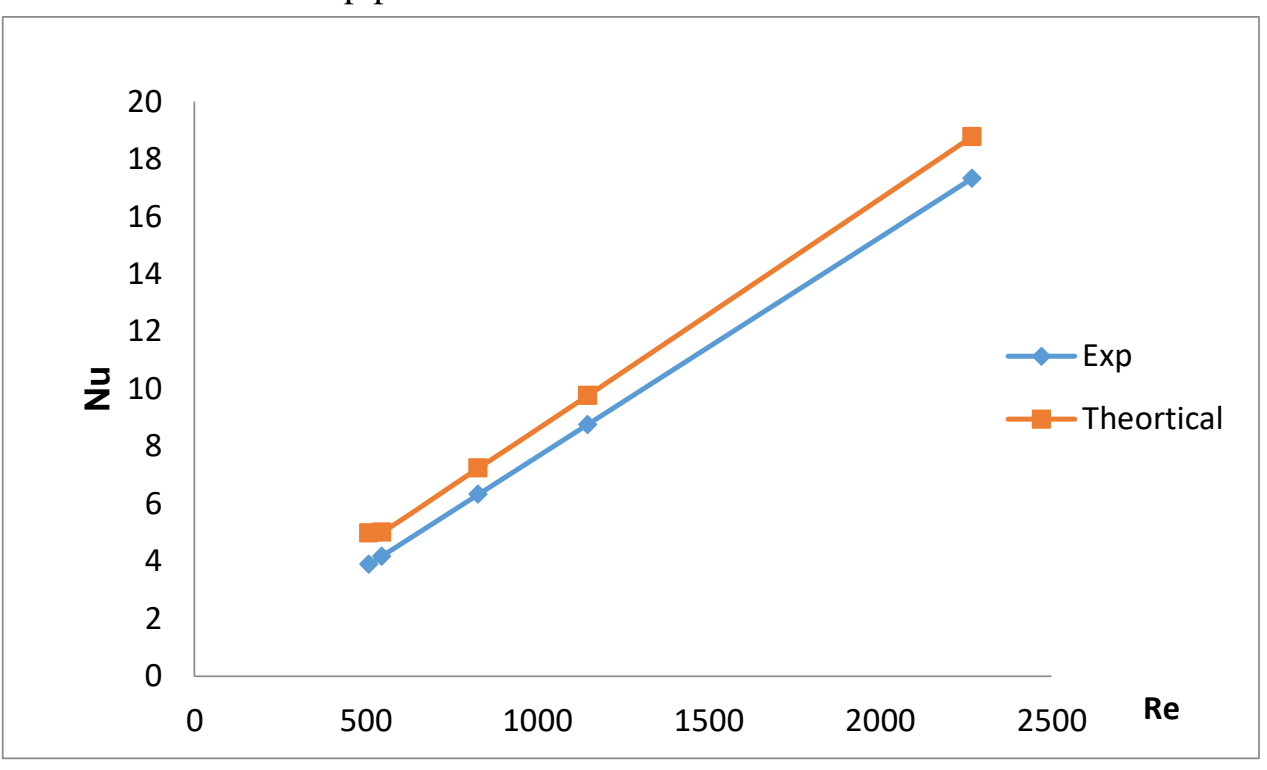

Nusselt No error percentage decrease in Nusselt to reach $10 \%$ at 2000 . Theoretical study depended on constant heat flux but in experiment Heat distribution unbalanced because of leakage flux due to using of Thermoelectric pad another thing is we neglect the contact resistance between grout and polyethylene pipe which gave a less resultant in total heat transfer resistance which physically increase the value of heat transfer coefficient and in the main domain increases the Nusselt Numbers.

Fig. (8): Comparison between Nusselt versus Reynolds Numbers Experimental \& Theoretical

Figure 9 show the efficiency of the prototype, which indicate the performance of max heat rate with Reynolds Number, device gave higher than $80 \%$ for the Reynolds No above 500, and its going down to reach $20 \%$ for Reynolds No. 2200, performance go down due to the effect of heat flow between double trenches far distances affected on performance with fluid have longer time stay in device. These curve can use as device phenomena to applied device as prototype from laboratory work and then can use it to improve the C.O.P around year for heat pump. 


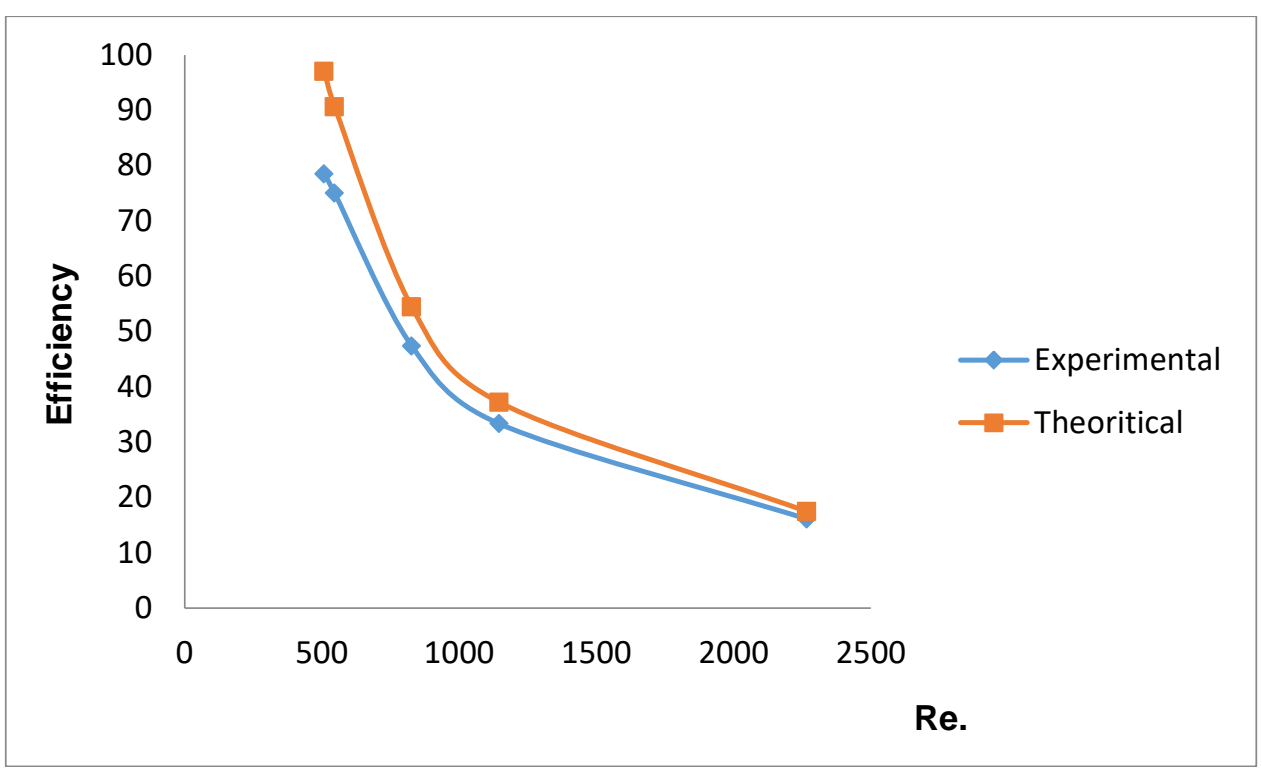

Fig. (9): Comparison of the efficiency with Reynolds number between experimental and theoretical

Figure 10 show the effectiveness of heat exchanger which found by using Equation 13 with Reynolds Numbers which show that effectiveness increase with low Reynolds No. because of time late inside heat exchanger also its mainly depended on fluid inlet temperature, this relation can gave idea to use variable flow rate with time.

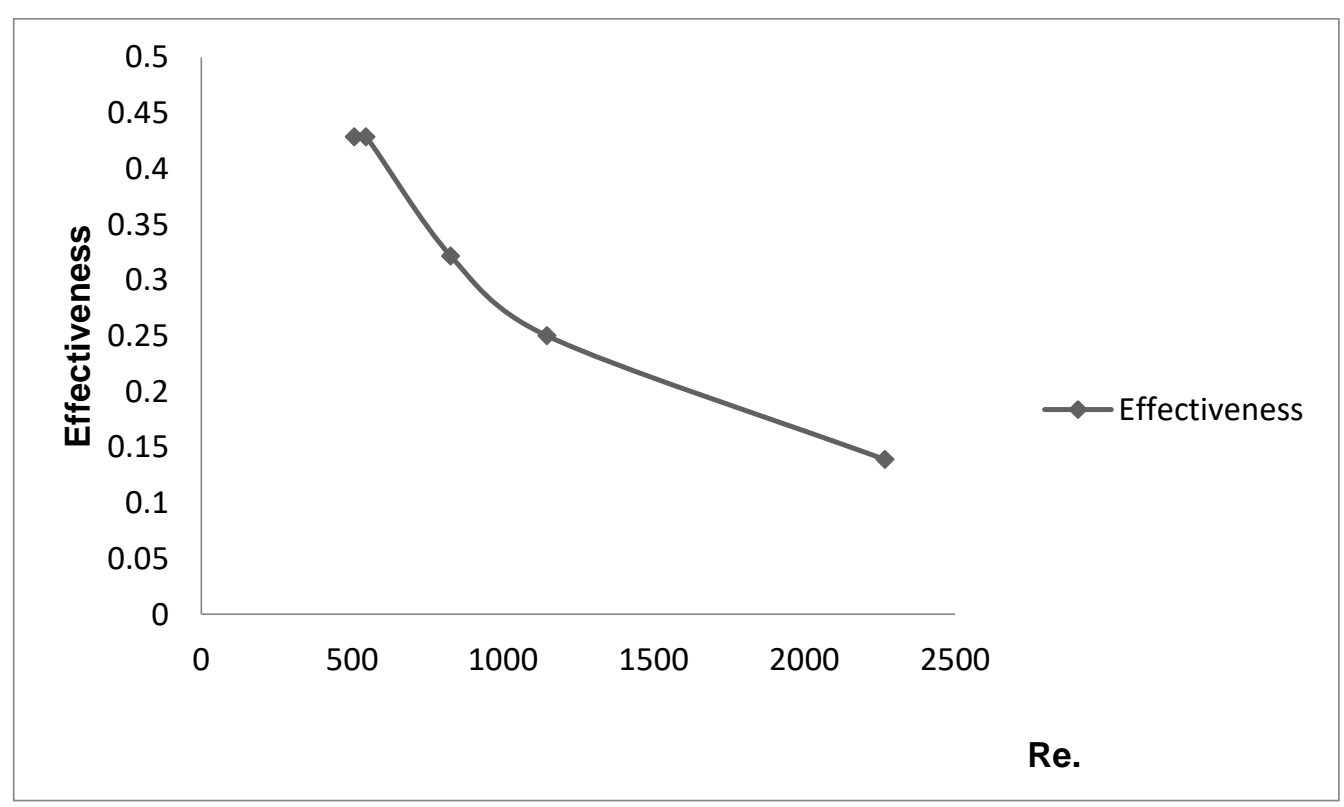

Fig. (10): Variation of Effectiveness with Reynolds Number

The energy efficiency of the HGHE is given by the NTU, shown in Figure 11. From This figure we can see that the efficiency increases with NTU, with the percentage from $16.3 \%$ to $95.4 \%$.The NTU determines with the residence time of the fluid inside pipes and thus also the amount of heat that it can sucked by the grout. Consequently when the NTU increases the residence time of the water in the heat exchanger increases which means at low speed and low Reynolds Numbers, thus the outlet temperature increases witch increase the energy efficiency. 


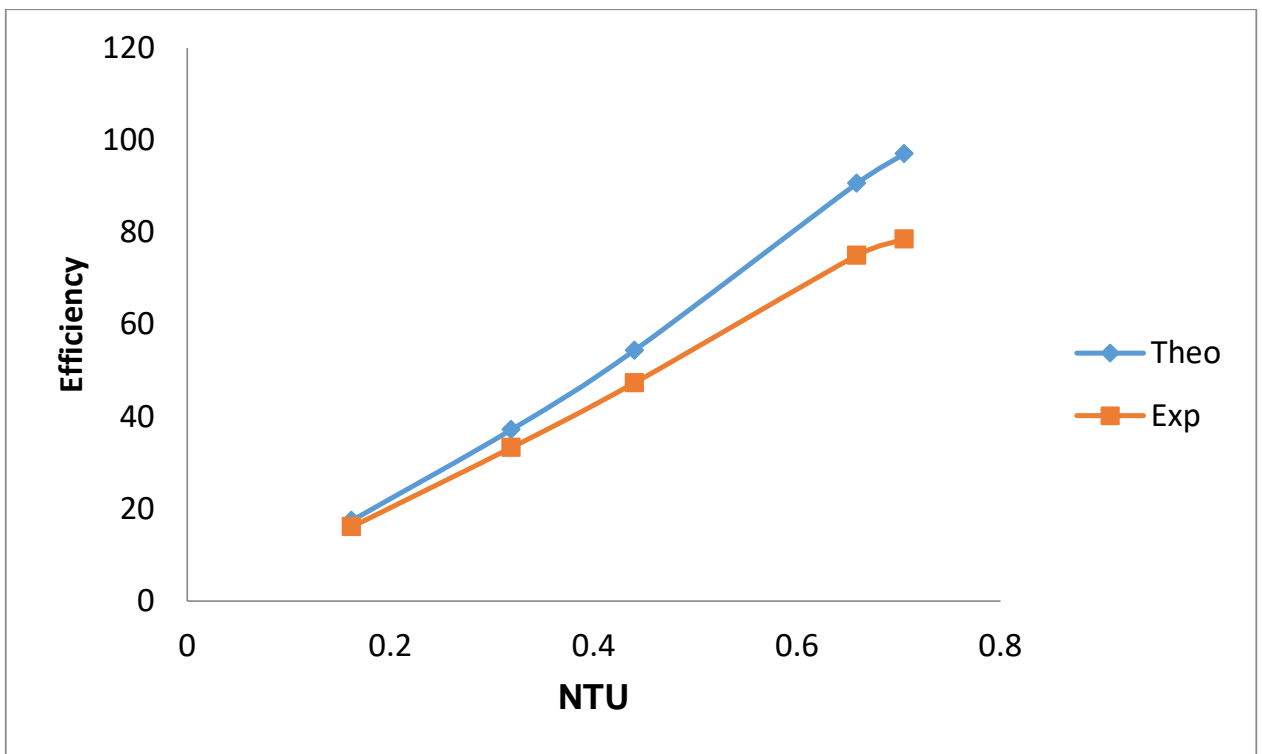

Fig. (11): Comparison of the NTU with Efficiency between experimental and theoretical

\section{5-CONCLUSION}

In the present study a prototype of horizontal ground heat exchanger was investigated in rectangular box and tested. Conclusions can be drawn from this study:

- A good result gave for the efficiency towards Reynolds number the difference between theoretical and experimental which indicate that the difference less than $1 \%$ for Reynolds Numbers $>2000$ and $17 \%$ for Reynold Number near 500. Which indicated that device can be for high Reynolds number as a prototype.

- The Heat exchange rate increase with Reynolds Number but effectiveness reduced.

- The experimental work is achieved with uncertainty analysis to reach the higher efficient value.

- The heat exchange rate, when the tempera outlet side of the exchanger is stabilized (steadystate), is about $5 \mathrm{~W} / \mathrm{m}$ with higher efficiency more than $80 \%$ at low $\operatorname{Re} \approx 500$, And increase to be around $11 \mathrm{w} / \mathrm{m}$ but with low efficiency around $20 \%$ at higher $\mathrm{Re} \approx 2200$ witch reflects the importance of surface geothermal energy for the designed rig.

- Using of Thermoelectric cooling system TEC12706 gave a suitable cooling system for the invited device.

\section{6- RECOMMENDATION}

* For the future work we suggest used different type of grout to reach higher efficiency by increase thermal conductivity of it then used it in actual case, also the pipe types with different material can use to reduce the resistance to increase heat flow.

* applied the same design with Air-conditioning to increase COP and performance specially in summer season with higher ambient Temperature.

\section{REFERENCES}

Chiasson, Andrew-Geothermal heat pump and heat engine systems _ theory and practice-Wiley (2016).

Kavanaugh, Stephen P._ Rafferty, Kevin D Geothermal heating and cooling _ design of ground-source heat pump systems-ASHRAE (2014).

Sarwo Edhy Sofyan, Eric Hu and Andrei Kotousov A new approach to modelling of a Horizontal geo-heat exchanger with an internal source term Applied Energy, 2016, vol. 164, issue C, 963-971.

J. Zhao, H. J. Wang, X. G. Li and C. S. Dai, "Experimen- . Meyer, "A Performance Comtal Investigation and Theoretical Model of Heat Transfer of Saturated Soil around Coaxial Ground Coupled Heat Exchanger," Applied Thermal Engineering, Vol. 28, No. 2-3, 2008, pp. 116-125.

McCartney JS, Rosenberg JE (2011) Impact of heat exchange on side shear in thermo-active foundations. In: Proceedings of the geofrontier 2011, ASCE, pp 488-498. 
Y. H. Bi, L. G. Chen and C. Wu, "Ground Heat Exchanger Temperature Distribution Analysis and Experimental Verification," Applied Thermal Engineering, Vol. 22, No. 2, 2002, pp. $183-189$.

Farouki, O.T., 1986. Thermal Properties of Soils. Series on Rock and Soil Mechanics, vol. 11. Trans Tech Publications, Clausthal-Zellerfeld.

A.K. Raja, Amit Prakash Srivastava, Manish Dwivedi.-Power Plant Engineering-New Age International (P) Ltd., Publishers (2006).

Jack P. Holman-Heat Transfer, Tenth Edition (McGraw-Hill Series in Mechanical Engineering) -The McGraw-Hill Companies, Inc. (2010).

Batini, N., Rotta Loria, A.F., Conti, P., Testi, D., Grassi, W., Laloui, L., 2015. Energy and geotechnical behavior of energy piles for different design solutions. Appl. Therm. Eng. 86 (1), 199_213.

Bergman, T., Incropera, F., Lavine, A., DeWitt, D., 2011. Fundamentals of Heat and Mass Transfer. Wiley, Hoboken, NJ.

Conti, P., Testi, D., Grassi, W., 2016. Revised heat transfer modeling of double-U vertical ground coupled heat exchangers. Appl. Therm. Eng. 106, 1257_1267.

Hellström, G., 1991. Ground Heat Storage: Thermal Analyses of Duct Storage Systems. Theory (Ph.D. Thesis). Department of Mathematical Physics, University of Lund, Lund.

Lyesse Laloui, Alessandro Rotta Loria - Analysis and Design of Energy Geostructures_ Theoretical Essentials and Practical Application-Academic Press

(2019). 